\title{
Tackling childhood obesity in the community using a participatory action research project with local children and young people
}

\author{
Katie Dharmarajah" ${ }^{*}$, Martha Fawcett ${ }^{2}$, Sarah Blackstock ${ }^{2}$, Arpana Soni ${ }^{2}$, Mando Watson ${ }^{2}$ and Mitch Blair ${ }^{1,3}$ \\ ${ }^{1}$ London North West University NHS Trust, UK \\ ${ }^{2}$ Imperial College Healthcare NHS Trust, UK \\ ${ }^{3}$ Imperial College London, UK
}

\begin{abstract}
Introduction: Co-production of health services is becoming more routine with young people but such involvement in research lags behind, especially in the field of health promotion research. Our aim was to co-design and test a community intervention with parents and children focused on changing lifestyle behaviours which might contribute to childhood obesity on a deprived local housing estate in London.

Methods: Within the context of an established integrated care collaborative, we supported parent and child volunteers to co-design and deliver a health and wellbeing intervention for local children. This was in the form of a 6-week "sprint" of exercise and healthy living activities. The subsequent evaluation was carried out by two children who were trained in basic qualitative and quantitative research methods by us. They designed, conducted and analysed data from intervention participants with repeat follow-up and analysis at 2 years.

Results: Twenty-six children were recruited with 12 completing the programme and 7 followed up for 2 years. Young people aged 12 and older universally felt they could communicate their views better in a focus group led by a local young person with established trust and agency. We observed the value of our peer evaluator's contribution to the design process and their insights during analysis.

Post programme there were improvements in physical activity and nutrition scores in participants using validated scores, and themes relating to healthy living which were retained at 2 years.

Discussion: The use of participatory evaluation in a citizen-driven intervention allowed us to breakdown barriers such as within hard to reach communities, as well as enabling more meaningful results. We have demonstrated the desirability and acceptability of participatory research with children and young people. This intervention also reinforces that small, community-designed and delivered initiatives have the power to effect behaviour change sustained at 2 years.
\end{abstract}

\section{Introduction}

Childhood obesity is an evolving public health crisis. In 2017 one in five UK children start primary school obese or overweight, which increases to more than one in three by the time they leave [1]. Data suggests that our 'obesogenic' environment [2] disproportionately impacts on those growing up and living in areas where there are health and social inequalities [2]. At age 5, children living in poverty are twice as likely to be obese as their least deprived peers, and by the age of 11 they are 3 times as likely [3].

A recent systematic review [4] found that targeted; schooldelivered, environmental or empowerment interventions to be the three most effective approaches in reducing socio-economic inequalities in obesity in this age group. Interventions that included behaviour change techniques, skills acquisition such as cooking skills, rewards and community-based resources were most effective. Elements deemed to be critical were those that were culturally appropriate and included parental engagement [5]. This is in keeping with the 2008 MRC guidance $[6,7]$ in the evaluation of complex interventions, which emphasises the importance of local adaptation of "core elements". The guidance encourages piloting and assessment of feasibility and acceptability of potential intervention approaches. The SHIFT-evidence [8] principles of: 'act scientifically and pragmatically'; 'embrace complexity'; and 'engage and empower' provided a framework for our group.

It is well described that the process of co-production creates more meaningful and effective interventions, however, evaluation and research tends to be clinician driven. Traditionally patients are viewed as participants in research, rather than active partners and this is even more so for children and young people's (CYP) involvement. The recent article by Preston, et al. [9] states "Everyone with a legitimate interest in research should be able to contribute to its design, review, conduct and dissemination" The NIHR INVOLVE advisory group defines involvement as 'research being carried out with or by CYP, rather than to, about or for them $[10,11]$. We wished to use such participatory research methods and involve parents and children in both the design

${ }^{\star}$ Correspondence to: Katie Dharmarajah, London North West University NHS Trust, River Island Centre for academic child health, Level 7 Maternity Northwick Park Hospital Watford Road, Harrow HA1 3UJ, UK, E-mail: k.dharmarajah@nhs.net

Received: December 17, 2019; Accepted: January 07, 2020; Published: January 10,2020 
of health promotion interventions and their evaluation in relation to adoption of healthy lifestyles and prevention of obesity.

\section{Methods \\ Background}

Connecting Care for Children (CC4C) [12] is an evaluated integrated care initiative which improves access to paediatric specialist care, multidisciplinary interactions through practice based meetings and engagement of practice champions. The practice champions (a concept described by Altogether Better) [13] in White city (a deprived locality with higher than average social housing, unemployment and poverty $[14,15]$ are local community members with an interest in child health, who volunteer at their GP practice to make change in their locality using a 'What Matters to Me' [16] approach. Health professionals in the area believed that there was little awareness amongst the community about local opportunities to facilitate healthy living and nutrition, and hypothesised that a programme to signpost, activities in the area and motivate individuals to take these up would improve behaviours and self-esteem. A bottom up approach aimed to bring local organisations together, support capacity building and empower and mobilize community members to create behaviour change across sectors. The programme was not funded and aimed to be resourced within existing assets to facilitate sustainability.

\section{Programme Design}

The programme, named "Parkview Olympics", consisted of a six week 'sprint' where young participants were encouraged to attend as many sports, exercise, and healthy living sessions as possible and track them using an activity planner. They were motivated with the prize of tickets to a QPR football game if they attended at least one activity per week. During the six weeks they were encouraged to wear a pedometer to track their daily steps. Opportunities were signposted with a timetable of all possible local activities (the majority of which were free and did not require pre-booking, if chargeable they were all $£ 1-5)$. The practice champions held regular sessions to touch base with participants, check their planners and signpost other opportunities.

\section{Participant selection}

Inclusion criteria for the programme were; age 8-12 and residence within the local borough. Being obese or overweight was not set as an inclusion criteria. There were strong feelings among the parents that the label of 'obese' was unhelpful, created stigma and reduced selfesteem and didn't help aid change. So the aim of the programme was not to help children lose weight, but to facilitate lifestyle change. In order to reduce stigmatisation of obese individuals the programme remained open to anyone in the community.

The idea to use young evaluators was raised early in the programme design with the local community. Two older siblings to participants were idenitified by the practice champions. They were both female, aged 12 and 13 at the time of the programme and both keen to engage. Only one participated with the 2 year follow up, as the older of the two was undertaking GCSEs at the time.

\section{Analysis}

Due to the scale and nature of the intervention it was not considered practical to have a comparator group. As a result, a before and after design was adopted.
Quantitative data was recorded from activities (for example, registers, activity planner, diary cards and pedometer steps) taken at baseline and the end of programme. Participants also recorded self-reported Physical activity, (using PAC-Q) Nutrition (using the CDQ) and Self Esteem Scores (using KidKINDL) with these validated tools at recruitment and at the end of the programme [17-19] This data was collected by the researchers from CC4C. Statisical analysis was performed using Microsoft ${ }^{c}$ Excel 2010(Microsoft corporation Washington USA) and Prism ${ }^{c}$ version 6.01 (GraphPad software, La Jolla, California, USA). The paired t-test was employed and statistical significance taken as $<0.05$.

Qualitative data was collected from post programme focus groups and semi-structured interviews with key stakeholders, participants and parents. A graphic facilitator was used during final focus groups with participants and parents to stimulate conversation and encourage creative thinking around a number of themes; awareness, knowledge, motivation, engagement and perceptions of children and their parents around the organisation of the programme.

The young evaluators were given training on evaluation methods and analysis and then participated in co-designing the structure, style and content of the post-programme focus groups for participants. It was then conducted by the young evaluators with adult researchers in the room but not in a position of leadership. The participants were split into smaller groups of 6-8 and the sessions were audio recorded, parents were not present during discussion. A parallel focus group for the parents was conducted by the research team at the same time.

The audio recordings were then transcribed by 2 members of the research team. Qualitative results were code, and analysed using thematic analysis using two members of the research team. The coding and theme identification was repeated with the two young evaluators and results compared and collated by the researchers and evaluators together.

2 years after the intervention completed the same children who participated initially were contacted and 7 former participants were recruited to attend focus groups. The session itself was co-designed between the research team and one of the two young evaluators who participated in 2017. She was supported with refresher training in research and evaluation. Again she led the group in 2 focus groups, with researchers present but not leading, and parents absent. Semistructured interviews were also conducted with the peer evaluator and her mother, the lead community champion involved in designing and implementing the programme.

Analysis was again conducted using thematic analysis in the same process as above. The same analysis technique was repeated for the semi-structured interviews.

\section{Results}

\section{Participants}

Twenty-six participants were recruited (capacity 30 places), aged 8-12 years. with equal numbers of boys and girls. Of these, 12 participants ( 6 of each gender) completed the full programme. Two year follow up data was collected on 7 young people, ( 3 girls , 4 boys) with an age range of $11-15$ years. Anthropometric measurements were completed on 17 participants. Four (24\%) were obese ( $>95^{\text {th }}$ centile), 3 $(18 \%)$ were overweight $\left(85^{\text {th }}-94^{\text {th }}\right.$ centile) and $10(58 \%)$ were healthy weight $\left(5^{\text {th }}-85^{\text {th }}\right.$ centile $)$. 


\section{Quantitative analysis immediately post intervention}

Table 1 shows the changes in self-reported pre and post intervention scores. An improvement was noted in all mean of differences. The improvements in activity levels and sugary snack intake were both statistically significant $(\mathrm{p}=<0.05)$

Chart 1 shows the number of steps recorded on the pedometer by participants throughout the programme, showing improvements week by week. However it should be noted that only 3 participants wore the pedometer for the whole course of the programme.

\section{Qualitative analysis}

Feedback was overwhelmingly positive. Themes that emerged included;

\section{Health benefits}

Participants and parents described benefits on both the children's physical and mental health, as well as healthier eating and skills around cooking.

- 'I really like the swimming because I get to dive in and it relaxes me instead of having so much stress.'

- 'It's good as it gets you to exercise regularly and you get better and better.'

\section{Social benefits}

The included time spent as family doing family activities, making new friends and reduced screen-time and improved confidence

\section{Average pedometer steps by weeks}

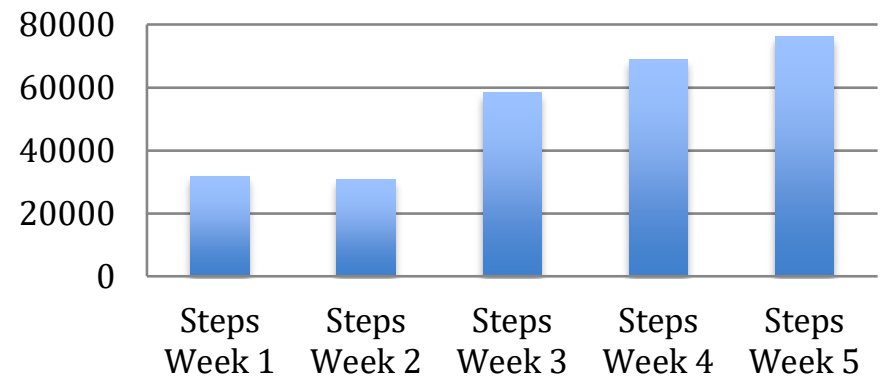

Chart 1. Shows the number of steps recorded on the pedometer by participants throughout the programme, showing improvements week by week
- 'It was really fun as we did tennis with our mum, I liked all spending time together as a family.

- 'I liked the basketball because I made new friends there.'

- 'If there is nothing to do then the only thing you do is play on your phone'

\section{Organisational relationships}

Stakeholders and practice champions highlighted improved organisational relationships and increases in the number of new participants to activities at their organisation.

- 'It's been great to work with each other and make new relationships with other organisations.'

- 'It's been really motivating for the practise champions. They have come together as a team really well.'

Other themes included the barriers to healthy living locally, the benefits of trying new things and the importance of having fun! Further themes are illustrated in the word art produced by the graphic designer (Figure 1).

\section{Qualitative analysis 2 years post intervention}

Two years on thematic analysis of peer designed and conducted focus groups was again performed by a minimum of 2 researchers in addition to one of the two young evaluators, so again 3 independent reviews of the transcripts were performed.

This showed the following themes;

The value of healthy eating and retained cooking skills

Participants reported improved knowledge of healthy eating, and cooking. They reported that these skills had been retained.

- 'From the cooking I learnt how to cook, now so I cook stuff at home'

- 'it benefitted me when it came to how to eat healthily and stay active and I think for sure I've been way more (healthy) after Parkview Olympics

- 'I learnt that healthy stuff doesn't always have to taste bad it can actually taste nice'

Ongoing participation in physical activities started during the Parkview Olympics

Not all children still participated regularly in the activities they started during the Olympics but many did. The most popular on-going

Table 1. Shows the changes in self-reported pre and post intervention scores

\begin{tabular}{|c|c|c|c|c|}
\hline & $\begin{array}{c}\text { Average Score } \\
\text { PRE } \\
\text { (range of scores) }\end{array}$ & $\begin{array}{c}\text { Average Score } \\
\text { POST } \\
\text { (range of scores) }\end{array}$ & $\begin{array}{l}\text { Mean of differences using paired } \\
T \text { test ( } 95 \% \text { confidence interval) }\end{array}$ & P Value \\
\hline $\begin{array}{l}\text { Activity } \\
\text { (using PAC-Q score) }\end{array}$ & $\begin{array}{c}2.9 \\
2.1-3.5)\end{array}$ & $\begin{array}{c}3.3 \\
(2.8-3.7)\end{array}$ & $\begin{array}{c}0.3 \\
(-0.1-0.8)\end{array}$ & $\mathrm{P}=0.099$ \\
\hline $\begin{array}{l}\text { Self Esteem } \\
\text { (using KidKINDL scale) }\end{array}$ & $\begin{array}{c}3.88 \\
(2.9-4.8)\end{array}$ & $\begin{array}{c}4.4 \\
(4.2-4.9)\end{array}$ & $\begin{array}{c}0.4 \\
(-0.1-0.9)\end{array}$ & $\mathrm{P}=0.11$ \\
\hline $\begin{array}{l}\text { Fruit and Vegetable Intake } \\
\text { (Using CDQ score) }\end{array}$ & $\begin{array}{c}8.9 \\
(3.6-11.4)\end{array}$ & $\begin{array}{c}18.1 \\
(10.9-22.1)\end{array}$ & $\begin{array}{c}9.3^{*} \\
(3.6-14.9)\end{array}$ & $\mathrm{P}=\mathbf{0 . 0 0 8 5}$ \\
\hline $\begin{array}{l}\text { No. of Takeaways in last } 7 \text { days } \\
\text { (Using CDQ score) }\end{array}$ & $\begin{array}{c}1.3 \\
(0-2)\end{array}$ & $\begin{array}{c}0.3 \\
(0-1)\end{array}$ & $\left(-2.3^{-1}-0.3\right)$ & $\mathrm{P}=0.11$ \\
\hline $\begin{array}{l}\text { Sugary snack intake } \\
\text { (Using CDQ score) }\end{array}$ & $\begin{array}{c}8.5 \\
(5-15)\end{array}$ & $\begin{array}{c}5.8 \\
(2-13)\end{array}$ & $\begin{array}{c}-2.6 * \\
(-2.1-3.2)\end{array}$ & $P=0.0001$ \\
\hline $\begin{array}{l}\text { Soft drink consumption } \\
\text { (Using CDQ score) }\end{array}$ & $\begin{array}{c}2.5 \\
(0-6)\end{array}$ & $\begin{array}{c}1.5 \\
(0-6)\end{array}$ & $\begin{array}{c}-1 \\
(-2.3-0.3)\end{array}$ & $\mathrm{P}=0.11$ \\
\hline
\end{tabular}




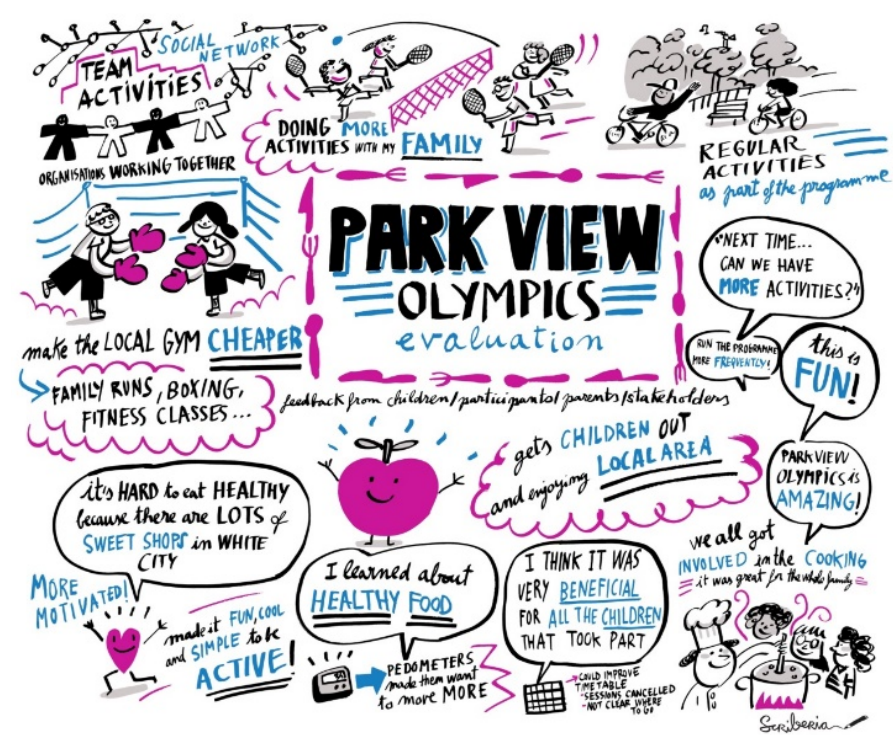

Figure 1. Themes are illustrated in the word art produced by the graphic designer

activities were boxing and football. Barriers to on-going participation discussed included school work and exams.

Self reported increased motivation around being active

Many children commented that they had remained more active in the last 2 years

- 'I think yeah because you get the benefit of doing sports and trying things you never have before, because after for sure I kept mainly going more active'

\section{Friendships and sense of community}

Participants reported meeting people they otherwise wouldn't have met and an improved sense of community on-going.

- 'You made new friends that you never seen before, never know before'

- 'You meet new people'

- 'they're not my friends (but now) I say hi and then bye to them'

- 'it creates a nice atmosphere'

- 'the fact you're okay to say hello to other people in your area'

\section{The value of peer evaluation}

We also assessed the perceived value of the peer evaluator. The participants aged 11 and under commented that they wouldn't mind if an adult or a young person had led the focus group. But this doesn't take into account the influence of the peer evaluator in designing the accessibility of the questions and ethos of the session. The participants aged 11 and over universally preferred having a peer evaluator.

- "(you) don't have to clarify yourself when speaking to young person"

- "Easier for them to understand what you say"

\section{The value of a locally known peer evaluator}

Analysis of the semi-structured interviews further emphasised the value of both the young person, but someone known and with agency with the participants. It highlighted the difficulty of gaining trust in this community as a whole, even more pronounced in young people.
- 'this community is a complicated one, for you (an outsider) to be trusted is difficult"

- 'I think it worked well because they were children from the community and so they were accepted'

- 'it's easier to talk with someone that you know, you can have an easy conversation'

The benefits for the peer evaluator herself included gaining new skills and having new opportunities.

- '(I chose to do it) to have a new experience, to do something different'

Further themes from the 2 year follow on focus groups can be seen in the following graphic illustration (Figure 2).

\section{Discussion}

\section{Summary}

Parkview Olympics was well accepted as a set of interventions in the local community and a number of participants retained some of the key behavioural changes two years later. Our findings are one of the first feasibility studies of peer evaluation of a health promotion programme in a local community setting.

The quantitative results demonstrated a statistically significant self reported improvement in activity levels and sugary snack intake following participation in the 6 week programme.

Qualitative analysis demonstrated benefits in improved selfconfidence, reduced screen time, community benefits in making new friends and spending time with family, and improved organisational relationships amongst stakeholders.

At 2 years participants reported on-going improved awareness of healthy living, improved motivation to stay active and on-going benefits for their community.

The researchers observed and evaluated the benefits of a participatory evaluation. The value of using a local young person was also clear in parallel to the value of the locally known parents in the recruitment and design, in establishing trust, creating connections and

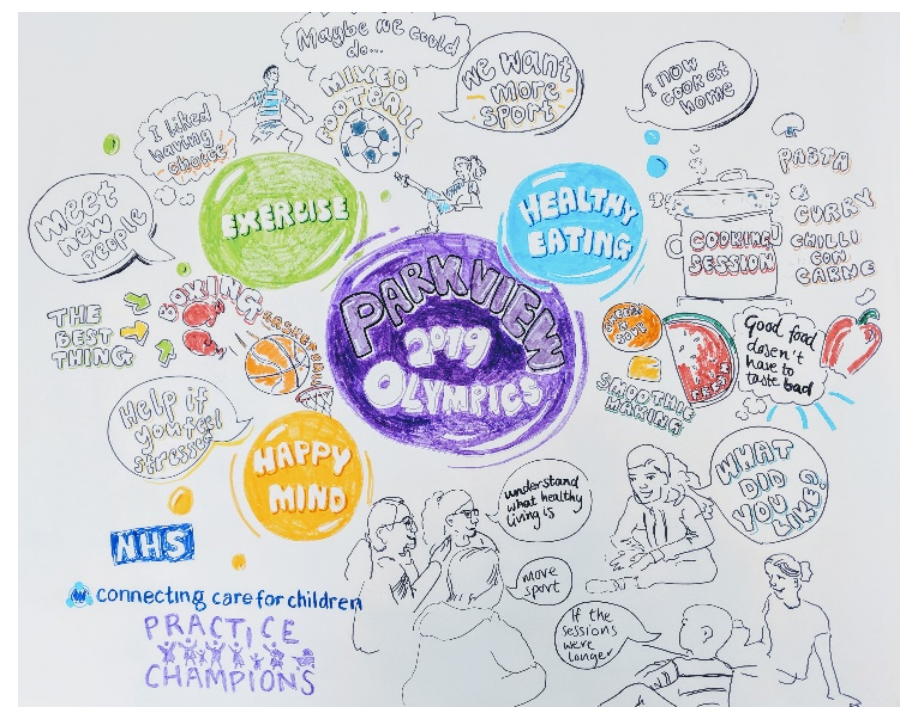

Figure 2. Themes from the 2 year follow on focus groups can be seen in the following graphic illustration 
breaking down barriers. We noted the accessibility of the questions and the young evaluators' input in the design of the focus groups. The participants commented on the ease of communication with a peer, and universally all aged over 11 reported they preferred a young evaluator to an adult. Their value in the analysis was undeniable in offering new perspectives on the findings.

\section{Conclusion}

Childhood obesity provides a major challenge and an expanding public health crisis. Traditional solutions are limited and developing interventions to tackle such complexity requires adaptability and a willingness to use novel approaches to seek locally feasible and acceptable interventions. Our project, although small scale, demonstrates the feasibility, value and richness of using a participant driven approach from inception to co-design and delivery in combination with participatory evaluation and builds the evidence base for future research projects in the field of health promotion.

\section{Funding}

$\mathrm{MB}$ receives funding from the National Institute for Health Research (NIHR) under the Applied Research and Care (ARC) programme for North West London.

Imperial College London provided a $£ 1000$ grant for academic trainee use called the CATO - this was used for training and expenses for the above project.

The views expressed in this publication are those of the author(s) and not necessarily those of the NHS, the NIHR or the Department of Health.

\section{Acknowledgments}

We would like to acknowledge the help of a wide group to make this intervention and analysis possible, in particular the Parkview Practice Champions and our young evaluators, but also Charlie Coughlan, Dougal Hargreaves, Bea Liddell, Rianne Steele, Bob Klaber and everyone at Connecting Care for Children.

\section{References}

1. NHS Digital, Statistics on Obesity (2017) Physical Activity and Diet, Health and Social Care Information Centre.
2. Living standards, poverty and inequality in the UK: $2017-18$ to $2021-22$, The Institute for Fiscal Studies.

3. Households Below Average Income (2019) Statistics on the number and percentage of people living in low income households for financial years 1994/95 to 2017/18, Tables $4 \mathrm{a}$ and $4 \mathrm{~b}$. Department for Work and Pensions.

4. Laws R, Campbell KJ, van der Pligt P, Russell G, Ball K, et al. (2014) The impact of interventions to prevent obesity or improve obesity related behaviours in children ( $0-5$ years) from socioeconomically disadvantaged and/or indigenous families: a systematic review. BMC Public Health 14: 779.

5. Bambra C, Hillier FC, Cairns JM, Kasim A, Moore HJ, et al. (2015) How effective are interventions at reducing socioeconomic inequalities in obesity among children and adults? Two systematic Reviews. Public Health Research p.3. [Crossref]

6. Campbell M, Fitzpatrick R, Haines A, Kinmonth AL, Sandercock P, et al. (2000) Framework for the design and evaluation of complex interventions to improve health. BMJ 321: 694-696. [Crossref]

7. Craig P, Dieppe P, Macintyre S, Michie S, Nazareth I, et al. (2008) Developing and evaluating complex interventions: the new Medical Research Council guidance. BMJ 337: a1655. [Crossref]

8. Julie E Reed, Cathy Howe, Cathal Doyle, Derek Bell (2019) Successful Healthcare Improvements From Translating Evidence in complex systems (SHIFT-Evidence): simple rules to guide practice and research, Int J Qual Health C 31: 238-244.

9. Preston J, Stones SR, Davies H, Phillips B (2019) How to involve children and young people in what is, after all, their research. Arch Dis Child 104: 494-500.

10. Involve (2018) Guidance on co-producing a research project. INVOLVE: Southampton.

11. Liabo K (2018) Roberts H Coproduction and coproducing research with children and their parents Arch Dis Child 104: 1134-1137.

12. www.cc4c.imperial.nhs.uk

13. https://www.altogetherbetter.org.uk/the-evidence-behind-our-work

14. https://www.ons.gov.uk/aboutus/transparencyandgovernance/freedomofinformationfoi/ incomebypostcode

15. https://www.lbhf.gov.uk/sites/default/files/section_attachments/borough-profile-2018

16. https://www.england.nhs.uk/what-matters-to-you/

17. Kowalski K (2004) The Physical Activity Questionnaire for Older Children (PAQ-C) and adolescents PAQ-A Manual. Kowalski KC, Crocker PRE, Donen RM, Saskatoon: University of Saskatchewan, Canada.

18. Magarey A, Golley R, Spurrier N, Goodwin E, Ong F (2009) Reliability and validity of the Children's Dietary Questionnaire; A new tool to measure children's dietary patterns. Int J Pediatr Obes 4: 257 265. [Crossref]

19. Health Related Quality of Life. Self esteem KidKINDL Validated Tool, 7-13 years.

Copyright: (C2020 Dharmarajah K. This is an open-access article distributed under the terms of the Creative Commons Attribution License, which permits unrestricted use, distribution, and reproduction in any medium, provided the original author and source are credited. 